\title{
Article \\ Supraoptimal Brassinosteroid Levels Inhibit Root Growth by Reducing Root Meristem and Cell Elongation in Rice
}

\author{
Kewalee Jantapo ${ }^{1,2}$, Watcharapong Wimonchaijit ${ }^{1}$, Wenfei Wang ${ }^{3}$ and Juthamas Chaiwanon ${ }^{1, *(D)}$ \\ 1 Center of Excellence in Environment and Plant Physiology, Department of Botany, Faculty of Science, \\ Chulalongkorn University, Bangkok 10330, Thailand; k.jantapo@gmail.com (K.J.); \\ watcharapong.wmcj@gmail.com (W.W.) \\ 2 Program in Biotechnology, Faculty of Science, Chulalongkorn University, Bangkok 10330, Thailand \\ 3 College of Life Sciences, Fujian Agriculture and Forestry University, Fuzhou 350002, China; \\ wenfeiwang@fafu.edu.cn \\ * Correspondence: juthamas.c@chula.ac.th
}

Citation: Jantapo, K.; Wimonchaijit, W.; Wang, W.; Chaiwanon, J. Supraoptimal Brassinosteroid Levels Inhibit Root Growth by Reducing Root Meristem and Cell Elongation in Rice. Plants 2021, 10, 1962. https:// doi.org/10.3390/plants10091962

Academic Editor: Andrzej Bajguz

Received: 26 August 2021

Accepted: 17 September 2021

Published: 20 September 2021

Publisher's Note: MDPI stays neutral with regard to jurisdictional claims in published maps and institutional affiliations.

Copyright: () 2021 by the authors. Licensee MDPI, Basel, Switzerland. This article is an open access article distributed under the terms and conditions of the Creative Commons Attribution (CC BY) license (https:// creativecommons.org/licenses/by/ $4.0 /)$.
Abstract: Root growth depends on cell proliferation and cell elongation at the root meristem, which are controlled by plant hormones and nutrient availability. As a foraging strategy, rice (Oryza sativa L.) grows longer roots when nitrogen $(\mathrm{N})$ is scarce. However, how the plant steroid hormone brassinosteroid (BR) regulates rice root meristem development and responses to $\mathrm{N}$ deficiency remains unclear. Here, we show that BR has a negative effect on meristem size and a dose-dependent effect on cell elongation in roots of rice seedlings treated with exogenous BR (24-epicastasterone, ECS) and the BR biosynthesis inhibitor propiconazole (PPZ). A genome-wide transcriptome analysis identified 4110 and 3076 differentially expressed genes in response to ECS and PPZ treatments, respectively. The gene ontology (GO) analysis shows that terms related to cell proliferation and cell elongation were enriched among the ECS-repressed genes. Furthermore, microscopic analysis of ECS- and PPZ-treated roots grown under $\mathrm{N}$-sufficient and N-deficient conditions demonstrates that exogenous BR or PPZ application could not enhance $\mathrm{N}$ deficiency-mediated root elongation promotion as the treatments could not promote root meristem size and cell elongation simultaneously. Our study demonstrates that optimal levels of BR in the rice root meristem are crucial for optimal root growth and the foraging response to $\mathrm{N}$ deficiency.

Keywords: brassinosteroid; propiconazole; nitrogen deficiency; root meristem; rice

\section{Introduction}

Root systems play important roles in water and nutrient acquisition. The developmental plasticity of root system architecture is crucial for crop adaptation to unfavorable environments, such as drought stress and nutrient deficiency stress. For example, rice varieties with larger root biomass, a more extensive root distribution, and a longer root length were found to use nitrogen more efficiently [1]. Understanding the mechanisms that control root growth is important for crop genetic improvement for sustainable agriculture, with the goal of reducing fertilizer application while maintaining crop productivity.

Root growth is determined by cell division and elongation at the root tip, where cells are organized along the longitudinal axis in distinct developmental zones. At the apical side of the root tip, cells are actively dividing in the meristem zone. As the cells leave the meristem zone, they enter the elongation zone, where they rapidly elongate and reach their mature size before entering the maturation zone to undergo differentiation [2]. Optimal root growth thus depends on the root meristem size and the number of dividing meristematic cells [3]. Several studies have demonstrated that root growth and meristem size are regulated by several internal and external factors, including plant hormones and nutrient availability in the soil [4]. 
Brassinosteroid (BR) is a class of steroid hormones that regulates various physiological processes such as hypocotyl cell elongation, photomorphogenesis, and stomatal development [5]. BR regulates rice and Arabidopsis root growth in a dose-dependent manner with low BR concentrations marginally promoting root growth and high BR concentrations dramatically inhibiting root growth [6,7]. Several BR and their roles in root meristem development have been studied using Arabidopsis roots as a model. Enhanced BR signaling results in premature cell cycle exit, and inhibits root meristem size in Arabidopsis [8]. In addition, previous transcriptomic analysis showed that BR promoted expression of cell elongation-related genes expressed in the root transition-elongation zone, but repressed several genes specifically expressed in the meristem zone [6].

Nitrogen $(\mathrm{N})$ is one of the most important macronutrients for plant growth and development, and it is frequently a key limiting factor in most agricultural systems. When grown under $\mathrm{N}$ deficiency, plants exhibit root foraging responses with increased root length, which allows them to explore more soil volumes to improve $\mathrm{N}$ uptake ability $[9,10]$. BR has been shown to regulate root adaptation responses to various nutrient deficiency including N, phosphorus, iron and boron [11]. Works in Arabidopsis have demonstrated that a natural allelic variation in a BR signaling component, BSK3, which leads to enhanced sensitivity of the BR signaling pathway, as well as upregulation of BR biosynthesis in roots, could promote primary root elongation under mild $\mathrm{N}$ deficiency [12,13]. However, it remains unclear how $B R$ regulates rice root meristem development and its responses to $\mathrm{N}$ deficiency.

In this study, we examined the effect of 24-epicastasterone (ECS) and propiconazole (PPZ), a BR biosynthesis inhibitor [14], on root meristem size and cell elongation in rice seedlings grown under $\mathrm{N}$-sufficient and $\mathrm{N}$-deficient conditions. Furthermore, we performed an RNA-sequencing analysis to identify ECS- and PPZ-responsive genes in the root under N-sufficient condition. Our results show that supraoptimal BR levels inhibited root cell proliferation and elongation, as well as expression of genes involved in cell proliferation and cell elongation and that optimal BR levels were crucial for $\mathrm{N}$ deficiency-induced root growth promotion.

\section{Results}

\subsection{Effect of BR on Root Elongation}

To investigate how BR modulates root growth, germinated rice seeds were grown for 5 days (d) in media supplemented with various concentrations of a biologically active BR, 24-epicastasterone (ECS), and/or a BR biosynthesis inhibitor, propiconazole (PPZ). Treatments of ECS at concentrations up to $10 \mathrm{nM}$ did not change primary root length, whereas 50 nM ECS inhibited root length significantly (Figure 1a,b). Increased PPZ concentrations resulted in more reduction in primary root length (Figure 1c). The inhibitory effect of $4 \mu \mathrm{M}$ PPZ on primary root length could be rescued by $1 \mathrm{nM}$ and $10 \mathrm{nM}$ ECS (Figure 1a,b). These results suggest that the effect of $\mathrm{BR}$ on root elongation is dose-dependent.

\subsection{Effect of BR on Root Cell Proliferation and Elongation}

To understand how BR regulates cell proliferation and elongation in the root apices, primary root tips of seedlings grown in the presence or absence of PPZ were treated with ECS for $24 \mathrm{~h}$ and observed under microscope. Quantification of cell number and cell length in the 4th cortical layer of the root meristem showed that PPZ treatment increased root meristem size and meristem cell number, but reduced cell length (Figure 2a-d). ECS treatments reduced meristem size and meristem cell number in a dose-dependent manner under both PPZ and no PPZ conditions. Treatment of $10 \mathrm{nM}$ ECS for $24 \mathrm{~h}$ could restore meristem size, meristem cell number and cell length of PPZ-treated roots to those of the untreated control (Figure $2 \mathrm{~b}-\mathrm{d}$ ). Higher concentrations of ECS strongly reduced meristem size and meristem cell number but did not further increase meristem cell length (Figure $2 \mathrm{~b}-\mathrm{d}$ ). This result suggests that BR had a negative effect on root meristem size and meristem cell number and a positive effect on meristem cell elongation. 
$\mathbf{a}$

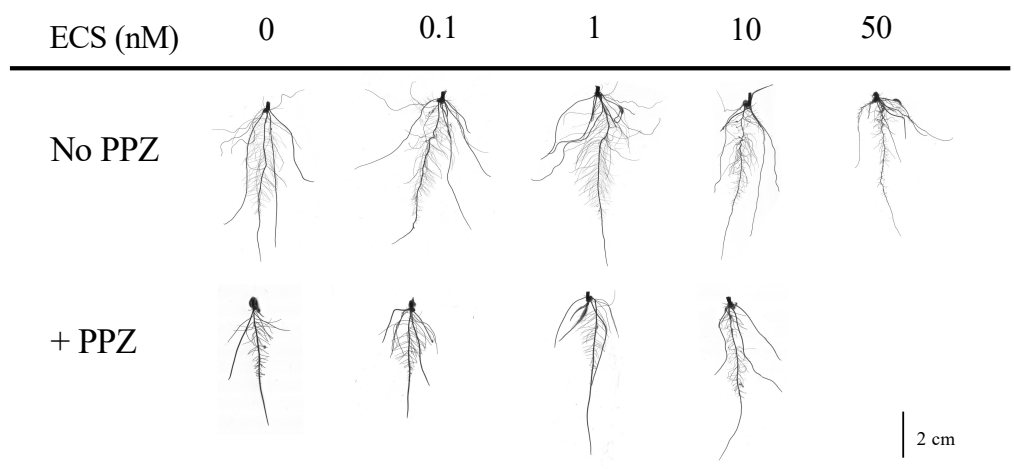

b

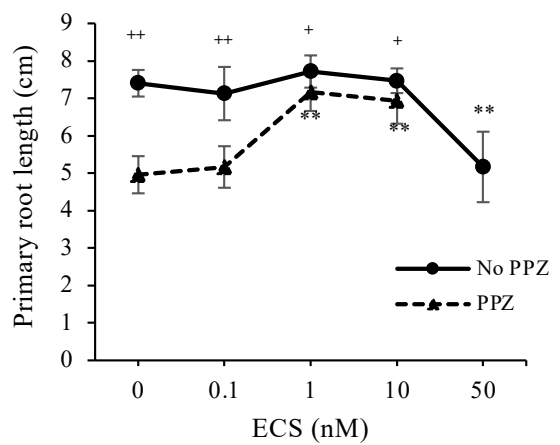

C

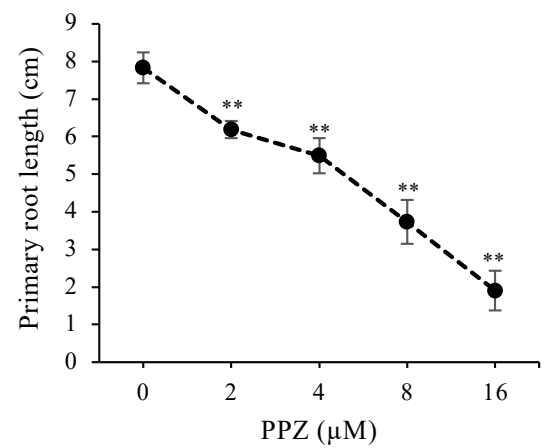

Figure 1. Effect of ECS and PPZ treatments on rice root growth. Root phenotypes of rice seedlings grown for $5 \mathrm{~d}$ under different concentrations of ECS or PPZ or combination of ECS and PPZ (4 $\mu \mathrm{M})$. (a) Representative images of roots grown under different treatments. Scale bar $=2 \mathrm{~cm}$. (b,c) Quantification of primary root length. Data are means $\pm \mathrm{SD}$ ( $n=10$ biological replicates). Significant differences between the treatment and the mock control are indicated by ${ }^{* *}$ for $p<0.001$. Significant differences between PPZ and no PPZ (with the same ECS concentration) are indicated by ${ }^{+}$and ${ }^{++}$for $p<0.05$ and 0.001 , respectively.

In addition to meristem cell proliferation, cell elongation in the elongation zone, which determines mature cell length, also contributes to root elongation rate. ECS treatment significantly reduced mature cell length. PPZ treatment also reduced mature cell length to $59 \%$ of the untreated control, which could be partially rescued by $1 \mathrm{nM}$ ECS (Figure 2e). However, higher concentrations of ECS could not promote cell elongation inhibited by PPZ (Figure 2e). The results show that BR had a dose-dependent effect on root cell elongation, with low concentrations promoting cell elongation and high concentrations inhibiting it.

\subsection{Transcriptome Profiling of ECS- and PPZ-Treated Rice Roots}

To understand how high and low (physiological) concentrations of BR regulate root elongation at transcriptional levels, we performed transcriptomic analysis of roots treated with a high concentration of ECS for $24 \mathrm{~h}(+\mathrm{ECS})$, or grown in media supplemented with PPZ (+PPZ) or without PPZ (mock). Expression profiles of ECS- and PPZ-treated samples were compared with the mock control (+ECS vs. mock and $+\mathrm{PPZ}$ vs. mock) to identify ECS- and PPZ-responsive genes, respectively. Genes that were significantly differentially expressed by more than 1.5 folds ( $\mid \log _{2}$ fold change $\mid>0.58$ and adjusted $p$-value $<0.05$ ) were included in the differentially expressed gene (DEG) list for further analysis. ECS treatment induced 696 genes and repressed 3414 genes, whereas PPZ treatment induced 991 genes and repressed 2085 genes (Figure 3a, Table S1). Venn diagram and heatmap clustering of DEGs show that about one-third of the PPZ-induced genes were also repressed by ECS, while there was little overlap between PPZ-repressed genes and ECS-induced or ECS-repressed genes. 

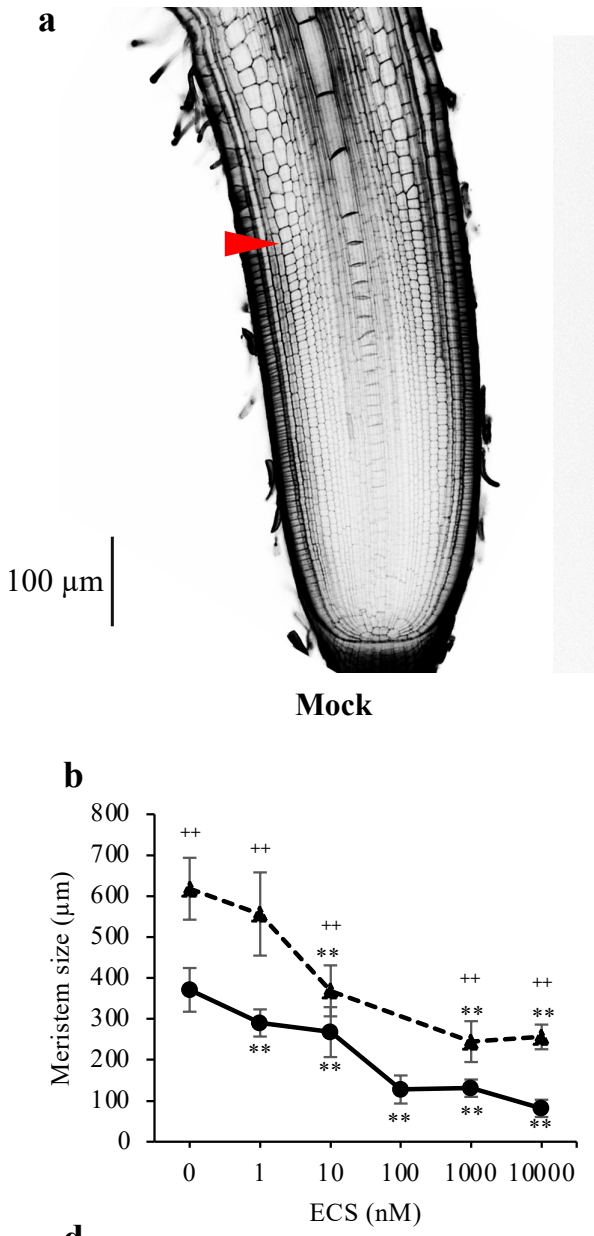

d

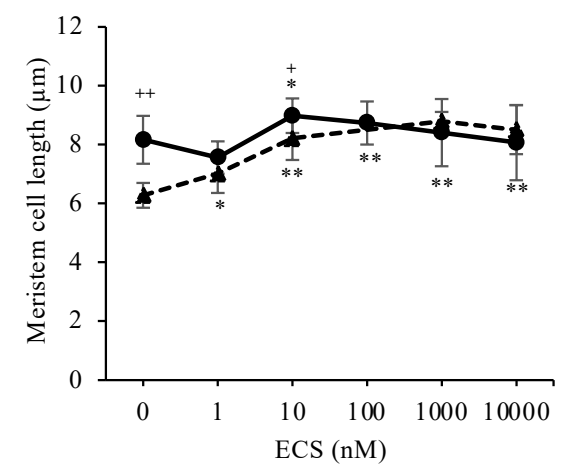

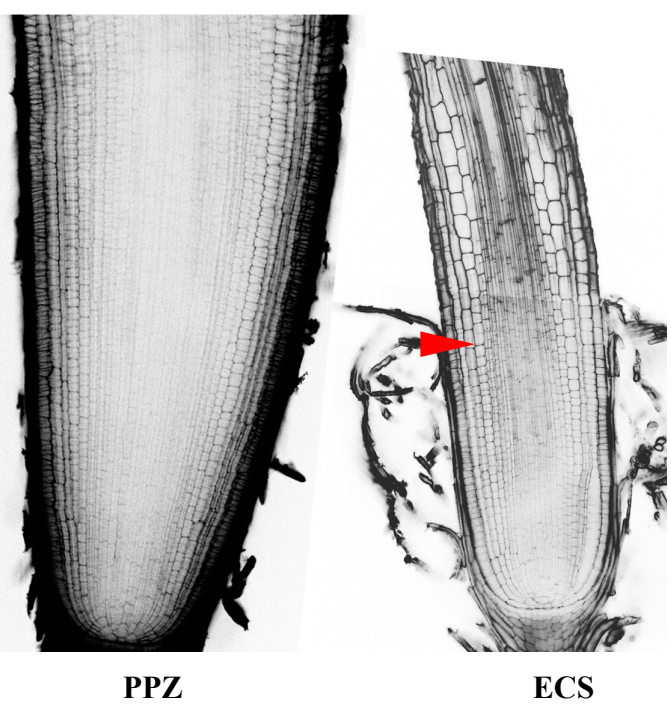

c
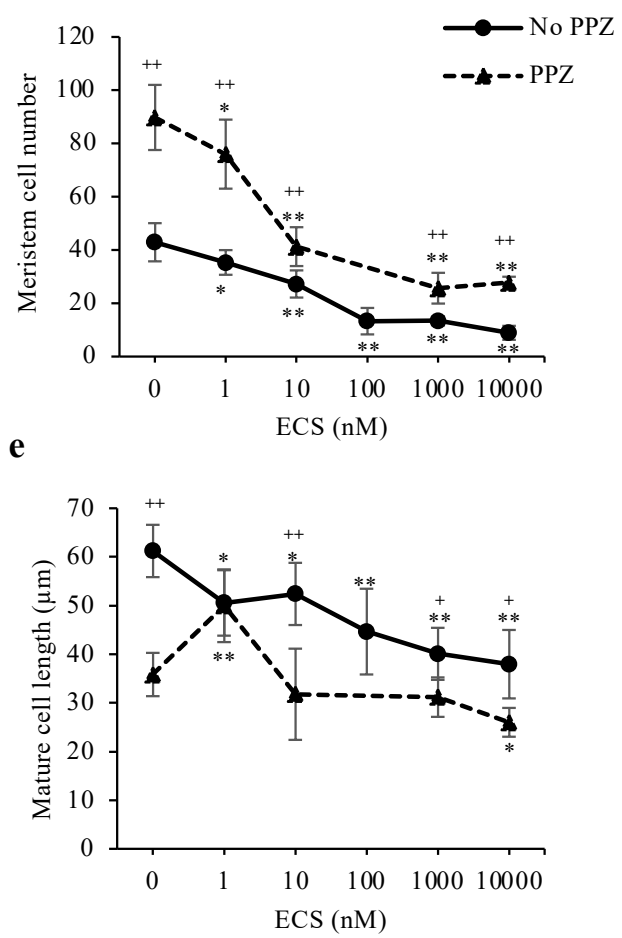

Figure 2. Effect of ECS and PPZ treatments on rice root meristem and cell elongation in primary root tips. Seedlings were grown in the absence and presence of PPZ for $5 \mathrm{~d}$, and then treated with ECS for $24 \mathrm{~h}$. (a) Confocal microscopy images of rice root meristems treated with mock, PPZ (4 $\mu \mathrm{M})$ or ECS $(10 \mathrm{nM})$. Scale bar $=100 \mu \mathrm{m}$. Arrowheads mark the end of the meristem zone; the PPZtreated root had large meristem that the end of the meristem zone was not present in the image. $(\mathbf{b}-\mathbf{d})$ Quantifications of root meristem size (b), meristem cell number (c) and average meristem cell length (d) were determined from cortical cells in the 4th cortical layer by measuring from the QC to the first elongated cell. Mature cell length (e) was determined from the average length of five adjacent mature cortical cells. Data are means $\pm \mathrm{SD}$ ( $n \geq 6$ biological replicates). Significant differences between the treatment and the mock control are indicated by * and ${ }^{* *}$ for $p<0.05$ and 0.001 , respectively. Significant differences between PPZ and no PPZ (with the same ECS concentration) are indicated by ${ }^{+}$and $^{++}$for $p<0.05$ and 0.001 , respectively. 
$\mathbf{a}$

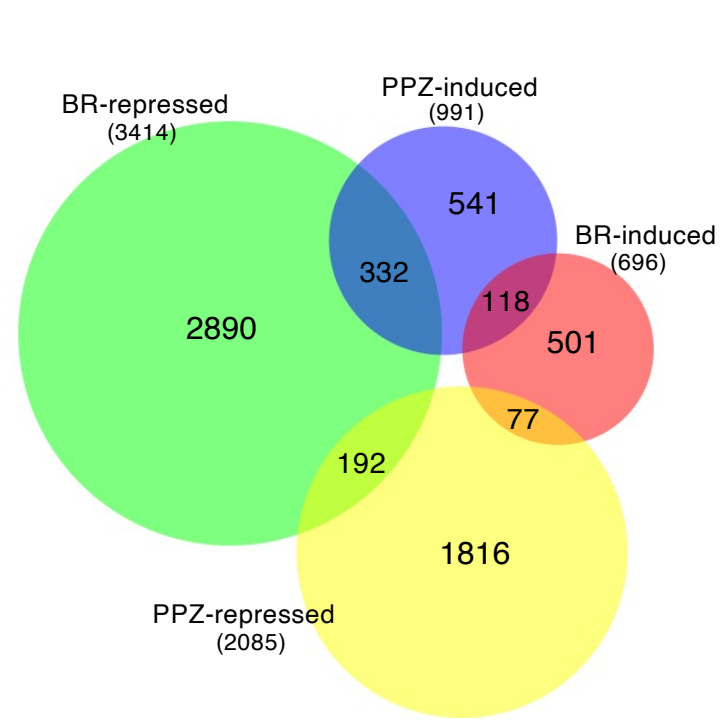

b

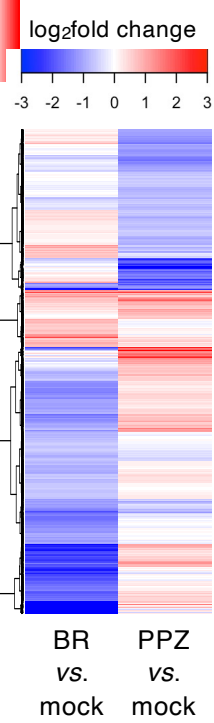

c

brassinosteroid biosynthetic process (GO:0016132)

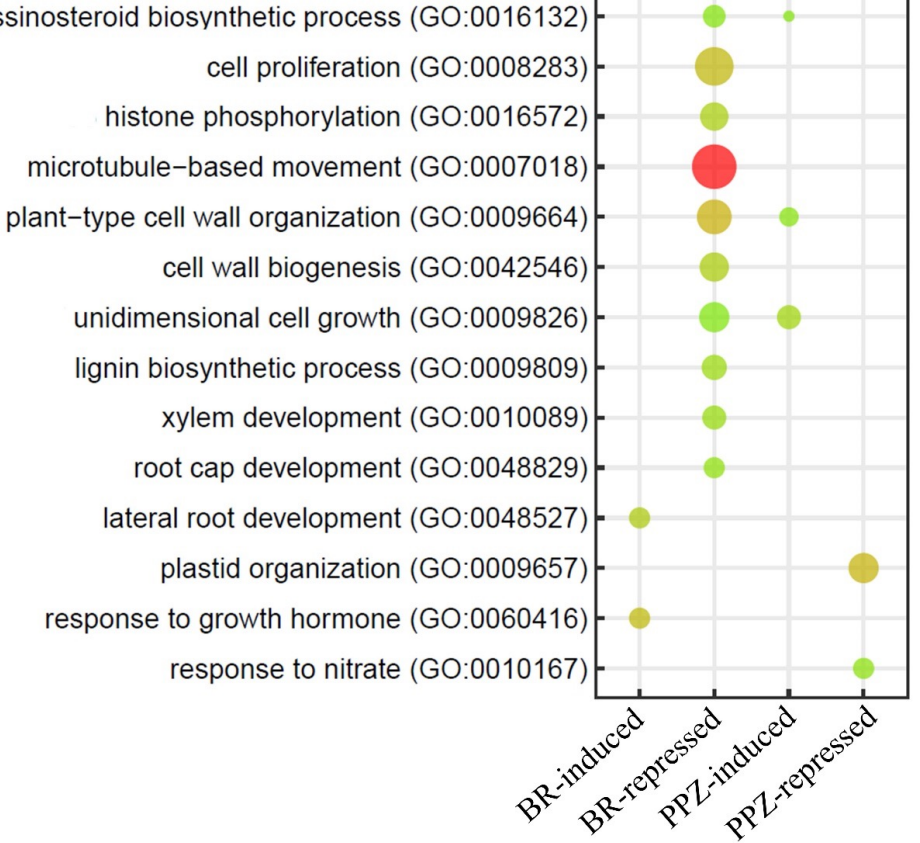

$-\log 10(F D R)$

$-10.0$

7.5

5.0

2.5

0.0

Number

of genes

- 10

20

30

Figure 3. Transcriptomic analysis of differentially expressed genes in ECS- and PPZ-treated rice roots. (a) Venn diagram showing the overlap between the lists of significant ECS-induced, ECS-repressed, PPZ-induced and PPZ-repressed genes ( $\mid$ fold change $\mid>1.5$; adjusted $p$-value $<0.05$ ). The numbers of DEGs are shown in parentheses. (b) Hierarchically clustered heatmap displaying the $\log _{2} \mathrm{FC}$ values of all significant genes in the ECS vs. mock or PPZ vs. mock comparisons. (c) GO biological process term enrichment analysis of the ECS and PPZ DEG lists.

Gene ontology (GO) enrichment analysis identified significantly enriched GO terms (biological process) among the ECS-repressed DEGs related to cell proliferation and cell elongation including 'cell proliferation', 'histone phosphorylation', 'microtubule-based movement', 'plant-type cell wall organization', 'cell wall biogenesis' and 'unidimensional cell growth' (Figure 3c). The terms 'lignin biosynthetic process', 'xylem development' and 'root cap development' were also enriched among the ECS-repressed DEGs, whereas the terms 'lateral root development' and 'response to growth hormone' were enriched among the ECS-induced DEGs. The terms 'plastid organization' and 'response to nitrate' were enriched among the PPZ-repressed DEGs. 
BR biosynthetic genes (OsBRD1, OsBRD2, OsD2, OsD11 and OsDWF4) were repressed by ECS and induced by PPZ, whereas BR catabolic genes (OsCYP73A2, OsCYP73A4 and OsCYP73A6) were induced by ECS and repressed by PPZ (Figure 4a). In addition, ECS repressed and PPZ induced expression of BR receptor genes (OsBRI1, OsBRL2 and OsBRL3) and BZR family transcription factors (OsBZR1, OsBZR2 and OsBZR4), with the exception of OsBZR4, which was induced by ECS (Figure 4a). The expression of these BR biosynthetic, catabolic and signaling genes, which showed negative feedback regulation by the BR signaling pathway [15], corroborated that BR signaling was activated in the ECS-treated roots and inhibited in the PPZ-treated roots.

a

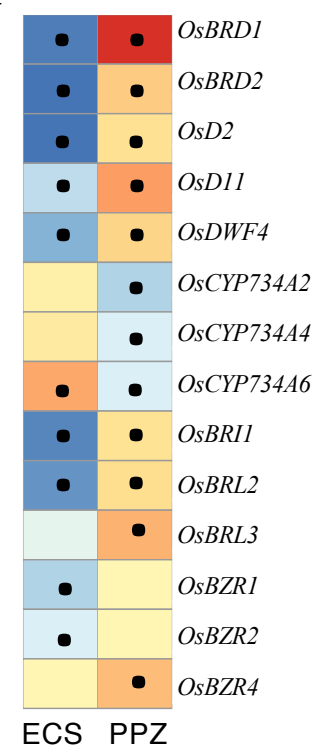

b

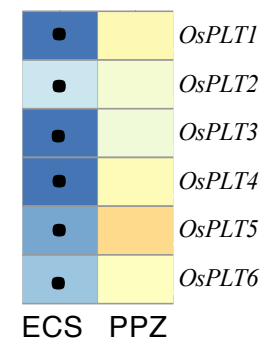

c

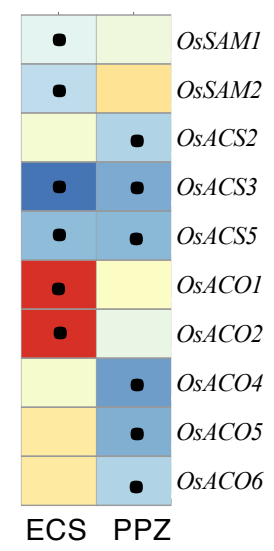

d

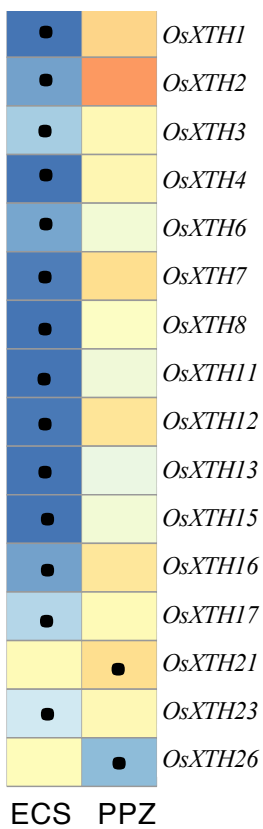

e

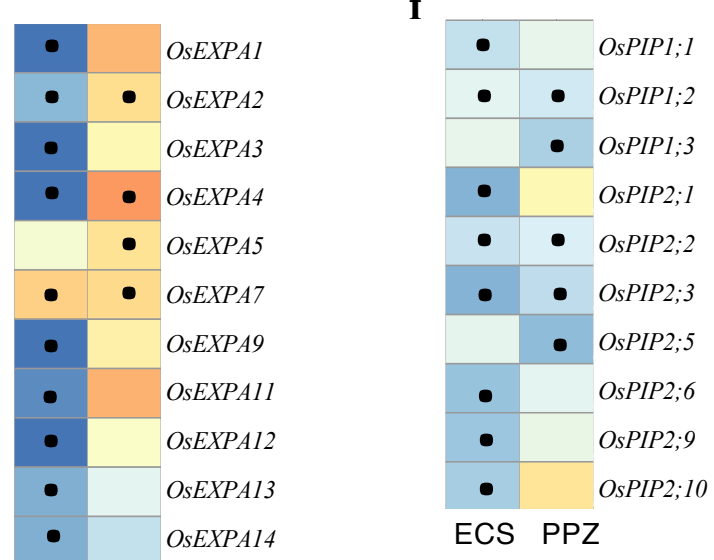

g

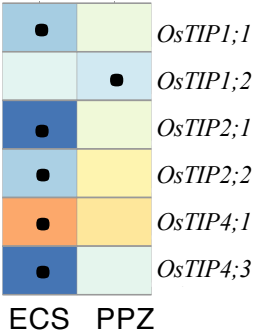

ECS PPZ

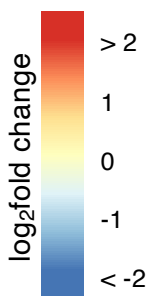

Figure 4. Expression of genes involved in BR biosynthesis and signaling, ethylene biosynthesis, cell proliferation and cell elongation. Heatmaps represent log2FC values of genes in the ECS vs. mock or PPZ vs. mock comparisons. Black dots indicate statistical significance of differential expression (adjusted $p$-value $<0.05$ ). (a) BR biosynthetic and signaling genes, (b) OsPLT genes, (c) ethylene biosynthesis genes, (d,e) cell wall loosening and remodeling genes OsXTHs (d) and OsEXPs (e), $(\mathbf{f}, \mathbf{g})$ aquaporin genes OsPIPs (f) and OsTIPs (g). Only genes that showed statistical significance in at least one of the ECS or PPZ comparisons were included in this figure.

The PLETHORA (PLT) family transcription factors are known to be master regulators of root meristem size [16]. Among 10 OsPLT genes identified in rice, OsPLT1-6, which are expressed in rice roots [17], were all repressed by ECS (Figure 4b). This result suggests that 
ECS inhibited root meristem size partly by repressing OsPLT expression. ECS also repressed several microtubule-related genes, which are involved in cell division [18]. These included 9 out of 12 tubulin genes, 27 out of 52 kinesin genes and 5 out of 11 microtubule-associated protein 65 (MAP65) genes identified in rice (Table S2).

Ethylene is another plant hormone that has been known to inhibit root elongation [19]. Ethylene biosynthesis is catalyzed by the enzymes S-adenosylmethionine (SAM) synthase, 1-aminocyclopropane-1-carboxylate (ACC) synthase (ACS), and ACC oxidase (ACO) [20]. We found that OsACO1 and OsACO2 were among the four strongest ECS-induced genes $\left(\log _{2}\right.$ fold change $=2.60$ and 2.23, respectively; Table S1), while OsACO4, OsACO5 and OsACO6 were significantly repressed by PPZ (Figure 3c), suggesting that ECS treatments may potentially increase ethylene contents by upregulating OsACO expression. However, genes encoding OsSAMS1/2 and OsACS2/3/5 were repressed by ECS and/or PPZ.

Expansins (EXP) and xyloglucan endotransglucosylase/hydrolase (XTH) play important roles in cell wall loosening and remodeling, thus mediating root cell elongation. We found that ECS treatment repressed 18 OsEXPAs, 6 OsEXPBs and 14 OsXTHs. PPZ treatment repressed 4 OsEXPAs and 1 OsXTH, but induced 3 OsEXPAs, 3 OsEXPBs and $1 \mathrm{OsXTH}$ (Figure 4d,e). In addition, ECS and PPZ repressed expression of aquaporins, including plasma membrane intrinsic proteins (PIPs) and tonoplast intrinsic proteins (TIPs), which are important regulators of osmotic water transport, cell turgor pressure and cell elongation [21]. ECS significantly repressed eight OsPIPs and four OsTIPs, while PPZ repressed five OsPIPs and one OsTIP. Only OsTIP4;1 was significantly induced by ECS (Figure $4 \mathrm{f}, \mathrm{g}$ ). These results suggest that a high concentration of BR inhibited root cell elongation by downregulating expression of most cell wall-loosening and remodeling enzymes and aquaporins. However, limited cell elongation caused by PPZ treatment is most likely due to reduced expression of aquaporins and certain expansins. The negative effect of high concentrations of ECS on cell proliferation and cell elongation-related genes suggests that optimal BR level in the root is critical for optimal root elongation.

\subsection{Effect of BR on N Deficiency-Induced Root Elongation}

To study how increased or decreased BR levels affect low N-mediated root elongation promotion, germinated seeds were grown in N-sufficient conditions (normal $\mathrm{N}$ ) for $5 \mathrm{~d}$ and then transferred to either normal $\mathrm{N}$ or low $\mathrm{N}$ conditions, which were supplemented with $10 \mathrm{nM}$ ECS or $4 \mu \mathrm{M}$ PPZ or mock. After $7 \mathrm{~d}$ of treatment, crown roots were used to measure growth and root meristems because the primary root of monocots dies as the plants age and had stopped growing in our experiment. Under low-N conditions, mock- and PPZ-treated roots had longer crown roots than normal N-treated roots, while ECS-treated roots had shorter roots (Figure 5a,b). Low $\mathrm{N}$ increased root meristem size, meristem cell number and mature cell length while decreasing meristem cell length (Figure $5 c-f)$. PPZ-treated roots had a larger meristem size than mock-treated roots, and low $\mathrm{N}$ did not increase it any further (Figure 5c). PPZ treatment, on the other hand, reduced the promoting effect of low $\mathrm{N}$ on mature cell length (Figure 5f), suggesting that endogenous BR is involved in root cell elongation in response to $\mathrm{N}$ deficiency.

Interestingly, ECS-treated roots were more strongly inhibited under low $\mathrm{N}$ compared to normal $\mathrm{N}$ conditions. In ECS-treated roots, low $\mathrm{N}$ treatment reduced meristem size and meristem cell number but allowed promotion of mature cell length (Figure $5 c, d, f$ ). Measurement of cell length in the 4th cortical layer along the longitudinal root axis demonstrates the point of transition into the elongation zone, where cells rapidly increase their length. Figure $5 \mathrm{~g}$ shows that ECS treatment caused premature cell cycle exit and that low $\mathrm{N}+$ ECS treatment enhanced cell elongation of the elongating cells, consistent with the further reduction in root meristem size (Figure $5 c, d$ ) and root length (Figure 5b). 
a

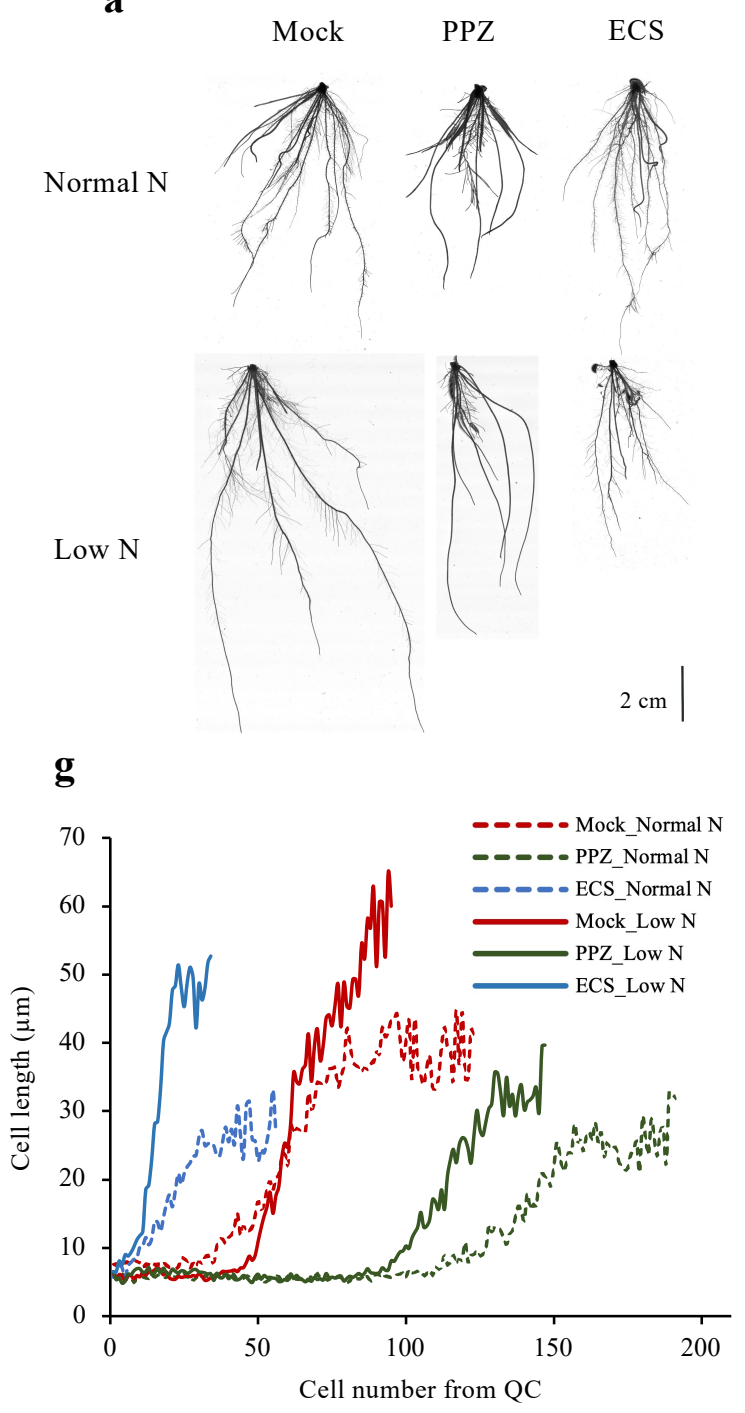

b
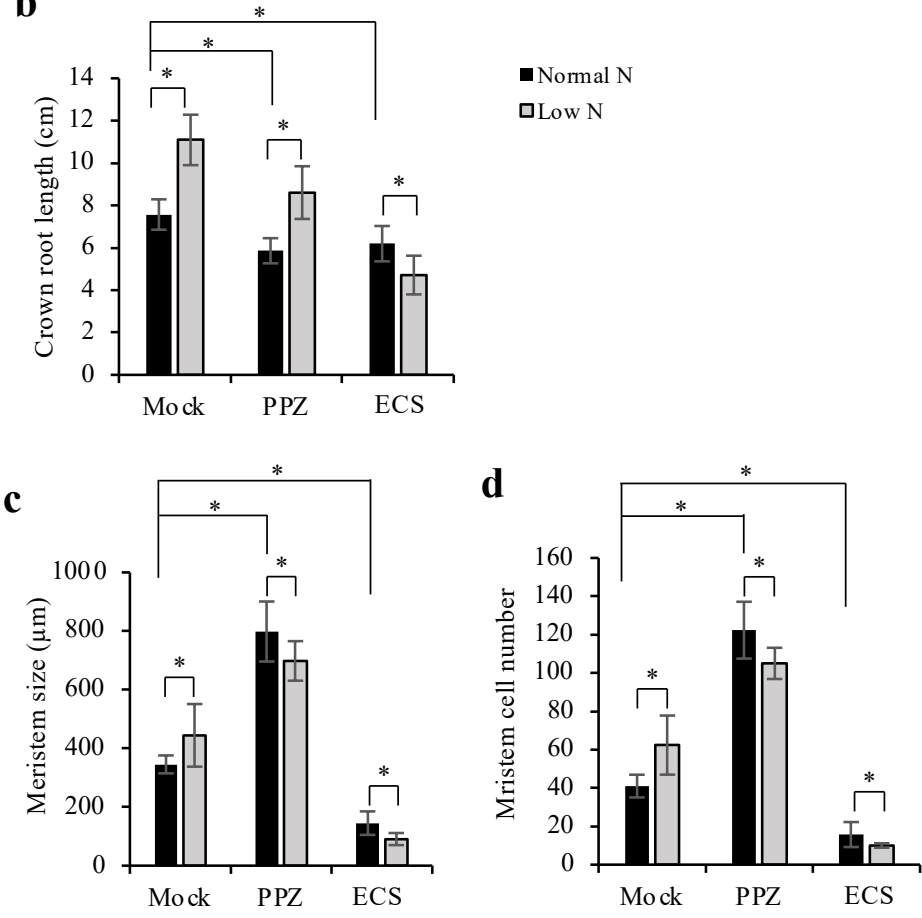

e
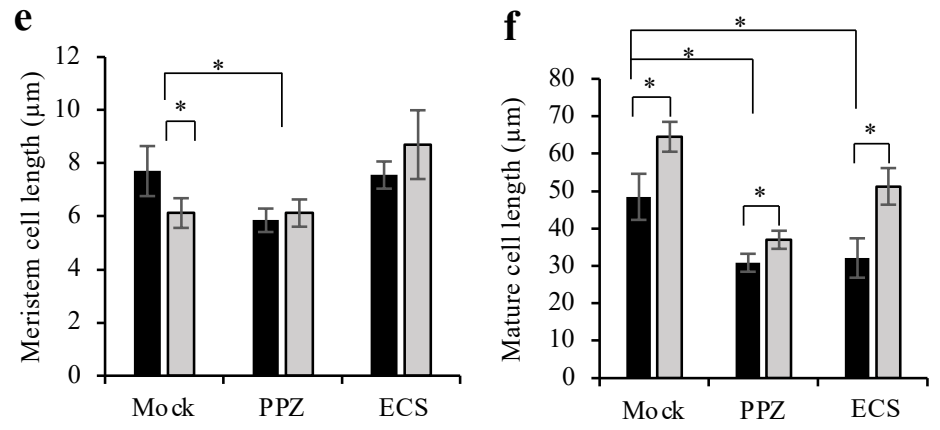

Figure 5. Effect of ECS and PPZ treatments on root growth responses to N deficiency. Germinated seeds were grown in normal $\mathrm{N}$ for $5 \mathrm{~d}$ and then transferred to either normal $\mathrm{N}$ or low $\mathrm{N}$ conditions containing $10 \mathrm{nM}$ ECS or $4 \mu \mathrm{M} \mathrm{PPZ}$ or mock for $7 \mathrm{~d}$. (a) Representative images of roots grown under different treatments. Scale bar $=2 \mathrm{~cm}$. (b) Crown root length was calculated from the average of the three longest crown roots. Data are means $\pm \operatorname{SD}(n=10$ biological replicates). $(\mathbf{c}-\mathbf{g})$ Quantifications of root meristem size (c), meristem cell number $(\mathbf{d})$ and average meristem cell length (e) in the crown roots were determined from cortical cells in the 4th cortical layer by measuring from the QC to the first elongated cell. Mature cell length (f) was determined from the average length of five adjacent mature cortical cells. (g) Average cortical cell length along the longitudinal root axis from the QC illustrated the number of cells in the meristem, the onset of rapid cell elongation and the effect of low $\mathrm{N}$ on promoting cell elongation under mock and ECS treatments but not PPZ treatment. Data are means $\pm \mathrm{SD}(n \geq 6$ biological replicates). Significant differences are indicated by * for $p<0.05$.

\section{Discussion}

Root length is a critical factor for crop productivity, as deeper roots can potentially increase soil exploration for water and nutrient uptake [22]. Optimal root growth depends on the size of root meristem, which is controlled by the balance between cell proliferation and cell elongation along the root developmental zones [23]. Here, we demonstrated that BR has a negative effect on meristem size and a dose-dependent effect on cell elongation in rice roots. Transcriptome analysis showed consistently that a high concentration of BR downregulated cell proliferation- and cell elongation-related genes. We then demonstrated that exogenous BR or PPZ application could not enhance root elongation promotion by 
$\mathrm{N}$ deficiency as the treatments could not simultaneously promote root meristem size and mature cell length.

\subsection{Effect of BR and PPZ on Rice Root Meristem Cell Proliferation and Cell Elongation}

$\mathrm{BR}$ has been shown to negatively regulate Arabidopsis root meristem size by promoting cell elongation and accelerating cell cycle exit [8]. As shown here, PPZ-treated roots exhibited reduced cell elongation and a large meristem size, likely due to a delay in cell cycle exit. Our results reveal that low concentrations of ECS could promote root cell elongation of the PPZ-treated meristematic and mature cells (Figure 2d,e), consistent with the well-known function of BR in promoting cell elongation in various plant species and tissues [24]. However, high concentrations of ECS significantly reduced mature cell length in rice roots. These observations together suggest that endogenous BR content in the elongation zone is closed to saturated for promoting cell elongation, whereas endogenous BR content in the meristem zone is supraoptimal for cell proliferation such that blocking BR biosynthesis led to increased root meristem size. The inhibitory effect of BR on rice root elongation reported here is consistent with previous findings. Upregulation of BR biosynthesis in rice roots by ammonium $\left(\mathrm{NH}_{4}{ }^{+}\right)$-induced miR444-OsBRD1 signaling cascade is responsible for $\mathrm{NH}_{4}{ }^{+}$-dependent root elongation inhibition [25].

\subsection{Transcriptional Regulation of Cell Proliferation- and Cell Elongation-Related Genes}

Transcriptome analysis showed that ECS significantly repressed OsPLT1-6 expression, consistent with the strong reduction of meristem size in the ECS-treated roots. Moreover, ECS also repressed expression of several tubulin, kinesin and microtubule-associated proteins, many of which have known function in cell proliferation and elongation [18]. These ECS-repressed kinesin genes included NACK-type kinesin-like protein (OsNACK), Gibberellin-deficient dwarf 1 (OsGDD1), and Stemless Dwarf 1 (OsSTD1), in which mutations led to impaired cell division and elongation [26-28]. In Arabidopsis, the BRactivated transcription factors BZR1 and BES1 have been shown to bind the promoter of the microtubule-associated protein CLASP gene and repress its expression, resulting in a drastic shift in microtubule organization and a reduction in root meristem cell number [29].

Ethylene has been shown to inhibit primary root elongation in rice by inhibiting root cell proliferation and elongation [30]. Although our results show that the upstream ethylene biosynthesis genes OsSAMS and OsACS were repressed by ECS, ECS strongly increased transcript of OsACO1 and OsACO2 (Figure 4c), which catalyze the final step of ethylene production. Thus, BR may increase ethylene levels, which could contribute to ethylene-mediated root elongation inhibition. Consistently, BR has been shown to increase ethylene production in etiolated rice seedlings through post-transcriptional regulation of ACS proteins [20]. Further research using ethylene signaling mutants or inhibitors of ethylene action is needed to confirm the crosstalk between BR and ethylene in inhibiting rice root elongation.

Inhibition of cell elongation by PPZ treatment was due to reduced expression of most aquaporins and some expansins. On the other hand, inhibition of cell elongation by ECS was due to reduced expression of the majority of aquaporins and cell wall-loosening and remodeling (EXP and XTH) proteins. EXP, XTH and aquaporin genes have been shown to be highly expressed in the elongation zone of Arabidopsis roots, and were induced by $\mathrm{BR}$ and repressed by auxin [6]. The contrast transcriptional regulation by BR in rice roots, as shown in this study, may be due to complex interaction of $B R$ with other signals that control cell elongation, such as ethylene and gibberellin (GA) [7,30]. Previous research has shown that elevated BR levels or BR signaling inhibit organ growth by promoting expression of the GA- inactivation enzyme GA2ox-3, which reduces bioactive GA levels and cell elongation in rice roots and leaf sheath $[7,31]$.

Taken together, our findings demonstrate the negative effect of high concentrations of BR on cell proliferation and cell elongation-related genes and suggest that optimal BR level in the root is critical for optimal root elongation. A recent study has demonstrated that 
optimal BR levels are required for root growth, as well as mineral nutrient homeostasis in soybean [32].

\subsection{Involvement of BR in Low N-Induced Root Elongation}

Root growth plasticity in response to nutrient availability is modulated by various phytohormones. Our results showed that $\mathrm{N}$ deficiency increased root meristem size, meristem cell number and mature cell length (Figure $5 c, d, f)$, consistent with a previous report [30]. A low concentration of BR treatment (10 nM ECS) inhibited low N-induced root growth, as it reduced root meristem size and meristem cell number but did not block low $\mathrm{N}$-induced cell elongation. On the other hand, PPZ treatment reduced low N-induced root growth, as it reduced low $\mathrm{N}$-induced cell elongation and did not further increase root meristem size and meristem cell number compared to the PPZ-treated roots in normal $\mathrm{N}$ condition.

Although results of ECS treatment under normal $\mathrm{N}$ condition suggest that endogenous BR level in the roots was optimal and likely saturated for root cell elongation, $\mathrm{N}$ deficiency could further promote root cell elongation. It is possible that $\mathrm{N}$ deficiency promoted root cell elongation by increasing very low levels of BR in the elongation zone or through non-BR-mediated processes. For instance, a recent work showed that $\mathrm{N}$ deficiency reduced cytokinin contents in rice primary roots, resulting in increased root meristem cell proliferation and cell elongation [17]. Further research is needed to quantify endogenous BR levels in the root tips to determine whether $\mathrm{N}$ deficiency alters BR contents in the root meristem zone and elongation zone, resulting in increased cell proliferation and elongation.

Patterning of hormonal signals along root developmental axis is critical for optimal root growth and development. Local BR biosynthesis has been shown to peak in the elongation zone [33], coinciding with the optimal onset of cell elongation in the transition zone located between the meristem and elongation zone. As a result, exogenous BR or PPZ treatment may not promote optimal root elongation due to unbalanced activity in the meristem and elongation zone.

\section{Materials and Methods}

\subsection{Plant Materials and Growth Conditions}

Seeds of rice (Oryza sativa L.) cv. Look Daeng Pattani, kindly provided by the Pathum Thani rice research center, were used in this study. Seeds were surface-sterilized and germinated in distilled water for $2 \mathrm{~d}$ in the dark, before transferring to Yoshida's nutrient solution (1.427 mM NH $\mathrm{mO}_{3}, 0.323 \mathrm{mM} \mathrm{NaH}_{2} \mathrm{PO}_{4}, 0.512 \mathrm{mM} \mathrm{K}_{2} \mathrm{SO}_{4}, 0.998 \mathrm{mM} \mathrm{CaCl}_{2}$, $1.643 \mathrm{mM} \mathrm{MgSO}_{4}, 0.009 \mathrm{mM} \mathrm{MnCl}_{2}, 0.075 \mu \mathrm{M}\left(\mathrm{NH}_{4}\right)_{6} \mathrm{Mo}_{7} \mathrm{O}_{24}, 0.019 \mathrm{mM} \mathrm{H}_{3} \mathrm{BO}_{3}, 0.152 \mu \mathrm{M}$ $\mathrm{ZnSO}_{4}, 0.155 \mu \mathrm{M} \mathrm{CuSO}_{4}$ and $0.036 \mathrm{mM}$ Fe-EDTA) [34]. The concentrations of N supply in normal $\mathrm{N}$ and low $\mathrm{N}$ conditions were $1.427 \mathrm{mM}$ and $0 \mathrm{mM} \mathrm{NH}_{4} \mathrm{NO}_{3}$, respectively. The nutrient solutions were adjusted to $\mathrm{pH} 5.8$ and renewed every $2 \mathrm{~d}$. The seedlings were grown in a growth room at $30^{\circ} \mathrm{C}$ with a $12 \mathrm{~h} / 12 \mathrm{~h}$ light-dark cycle.

To investigate the effect of PPZ and BR on primary root elongation, germinated rice seeds were grown for $5 \mathrm{~d}$ in normal $\mathrm{N}$ solution supplemented with various concentrations of PPZ $(0,2,4,8$ and $16 \mu \mathrm{M}$ PPZ) or ECS $(0,0.1,1,10$ and $50 \mathrm{nM}$ ECS) or the combination of $4 \mu \mathrm{M}$ PPZ and ECS (0, 0.1, 1 and $10 \mathrm{nM}$ ECS). To investigate the effect of PPZ and BR on primary root meristem and transcriptomes, germinated rice seeds were grown for $5 \mathrm{~d}$ in normal $\mathrm{N}$ media supplemented with or without $4 \mu \mathrm{M}$ PPZ and then treated with various concentrations of ECS $(0,1,10,100 \mathrm{nM}$ and 1 and $10 \mu \mathrm{M})$ for $24 \mathrm{~h}$. Only PPZ $(4 \mu \mathrm{M})$, ECS $(10 \mu \mathrm{M})$ and mock samples were included in the transcriptomic experiment.

For $\mathrm{N}$ deficiency experiments, germinated seeds were grown in normal $\mathrm{N}$ solution for $5 \mathrm{~d}$ and then transferred to either normal $\mathrm{N}$ or low $\mathrm{N}$ conditions, which were supplemented with $10 \mathrm{nM}$ ECS or $4 \mu \mathrm{M}$ PPZ or mock, and continued to grow for $7 \mathrm{~d}$. Root samples were harvested for quantification of crown root length, which was calculated from the average of the three longest crown roots, and crown root meristem. 


\subsection{Chemical Treatment}

This study used 24-epicastasterone (ECS), which is a precursor of castasterone, an end product of BR biosynthesis pathway in rice [35], and has been shown to be biologically active but less so than brassinolide [36]. ECS (Yuanye Biology, Shanghai, China), was dissolved in $80 \%$ ethanol. Propiconazole (Syngenta, Shanghai, China) was prepared by dissolving in distilled water. For mock treatment, medium with ethanol at the same final concentration as that for ECS treatments was used.

\subsection{Quantitative Analysis of Root Phenotypes}

Root systems were harvested and scanned using a flatbed scanner (EPSON Perfection V850 Pro, Japan), and root length was measured using ImageJ software (https: / imagej. nih.gov/ij/). For root meristem quantification, root tips were cut and incubated in a basic solution $(7 \% \mathrm{NaOH}$ in $60 \%$ ethanol) for $2 \mathrm{~d}$. Then, the roots were mounted in a solution (50\% glycerol in 10\% ethanol) [37], and imaged with a microscope (Olympus BX43, Japan). For confocal images of root meristem, the root tips were fixed in fixative (50\% methanol and $10 \%$ acetic acid) at $4{ }^{\circ} \mathrm{C}$ for at least $12 \mathrm{~h}$ and then stained using modified pseudo-Schiff propidium iodide (mPS-PI) staining [38]. Briefly, the tissue was incubated in $1 \%$ periodic acid, rinsed with water, and then incubated in Schiff reagent $(100 \mathrm{mM}$ sodium metabisulphite and $0.15 \mathrm{~N} \mathrm{HCl}$ ) with propidium iodide. The stained samples were mounted on microscope slides with a chloral hydrate solution and visualized on a Zeiss confocal microscope (Carl Zeiss, Oberkochen, Germany).

Root meristem size was determined by measuring the length from the quiescent center (QC) to the first elongated cell in the fourth cortical layer. Meristem cell number and meristem cell length were determined from the number of cells and the average length of all cells in the fourth cortical layer of the root meristem, respectively. Mature cell length was quantified from the average length of five adjacent mature cells in the fourth cortical layer of the root maturation zone, where cells have recently reached their final size within the treatment period. The meristem size and cell length were measured using ImageJ software.

\subsection{RNA Extraction, cDNA Library Construction and RNA-Seq}

For each treatment, three biological replicates (6 plants/ replicate) were included. Total RNA was extracted from root tissues using PureLink RNA Mini Kit based on the manufacturer's instructions (Invitrogen, Carlsbad, CA, USA) and genomic DNA were removed using DNase I (Thermo Fisher Scientific, Waltham, MA, USA). The quality of the total RNA was assessed by the Agilent 2100 Bioanalyzer (Agilent Technologies, Santa Clara, CA, USA), and all samples had an RNA integrity number (RIN) greater than 8.9. Purification of mRNA, library construction and sequencing were performed at Apical Scientific Sdn. Bhd. (Selangor, Malaysia) using an Illumina NovaSeq 6000 sequencer according to the manufacturer's instructions (Illumina, San Diego, CA, USA) for $2 \times 150$ bp paired-end reads. The RNA-seq raw data were deposited in the Sequence Read Archive of the National Center for Biotechnology Information under accession number PRJNA753856.

\subsection{Data Processing and Bioinformatics Analysis}

After pre-processing and filtering low-quality reads, more than $90 \%$ of reads could be mapped to the RAPDB reference genome (IRGSP 1.0.21) using HISAT [39] and StringTie [40] pipeline. Comparison of expression profiles was performed using DESeq2 [41]. The significant cutoff for differentially expressed genes was set at adjusted $p$-value $<0.05$ and | fold change | $>1.5$ (equivalent to I shrunken $\log _{2}$ fold change $\mid>0.58$ ).

Gene ontology (GO) enrichment analysis was performed using Plant Regulomics [42] with default parameters set and a threshold false discovery rate $(\mathrm{FDR})<0.02$ and plotted by REVIGO [43]. Hierarchical clustering and heatmap analysis were performed using 'hclust' and 'heatmap.2' packages in R (version 3.5.3). Venn diagram was plotted using DeepVenn (https://www.deepvenn.com). Heatmaps showing expression levels of selected genes were plotted using ClustVis web tools [44]. 


\subsection{Statistical Analysis}

For quantitation of root length and root meristem, at least ten and six biological replicates were analyzed, respectively. Means and standard deviation (SD) were calculated and analyzed by Student's $t$-test using IBM SPSS statistics 20 .

\section{Conclusions}

Our results show that supraoptimal BR inhibited root meristem size and cell elongation, while PPZ treatment increased root meristem size but also inhibited cell elongation. Transcriptome analysis reveals that ECS and PPZ treatments regulated several genes involved in cell proliferation and cell elongation. Furthermore, the responses of ECS- and PPZ-treated roots under N deficiency show that neither an excess nor an absence of BR could promote the root foraging response. Our findings highlight the crucial roles of optimal BR levels in the rice root meristem for maintaining the balance of cell proliferation and cell elongation to promote root growth.

Supplementary Materials: The following are available online at https:/ /www.mdpi.com/article/10 .3390/ plants10091962/s1, Table S1: ECS- and PPZ-differentially expressed genes; Table S2: Expression of microtubule-related genes.

Author Contributions: Conceptualization, K.J. and J.C.; Formal analysis, K.J., W.W. (Watcharapong Wimonchaijit) and J.C.; Methodology, K.J. and J.C.; Supervision, W.W. (Wenfei Wang) and J.C.; Validation, K.J.; Writing —original draft, K.J. and J.C.; Writing-review \& editing, K.J., W.W. (Wenfei Wang) and J.C. All authors have read and agreed to the published version of the manuscript.

Funding: This research was funded by the Thailand Research Fund and the Office of Higher Education Commission (grant number MRG-6180270) to J.C. and Science Achievement Scholarship of Thailand (SAST) scholarship and Chulalongkorn University Graduate School Thesis Grant to K.J.

Institutional Review Board Statement: Not applicable.

Informed Consent Statement: Not applicable.

Data Availability Statement: The RNA-seq data for all samples are available at the Sequence Read Archive of the National Center for Biotechnology Information under accession number PRJNA753856.

Acknowledgments: The authors would like to thank Supachitra Chadchawan for advice on the project.

Conflicts of Interest: The authors declare no conflict of interest. The funders had no role in the design of the study; in the collection, analyses, or interpretation of data; in the writing of the manuscript, or in the decision to publish the results.

\section{References}

1. Ju, C.; Buresh, R.J.; Wang, Z.; Zhang, H.; Liu, L.; Yang, J.; Zhang, J. Root and shoot traits for rice varieties with higher grain yield and higher nitrogen use efficiency at lower nitrogen rates application. Field Crop. Res. 2015, 175, 47-55. [CrossRef]

2. Perilli, S.; Di Mambro, R.; Sabatini, S. Growth and development of the root apical meristem. Curr. Opin. Plant Biol. 2012, 15, 17-23. [CrossRef] [PubMed]

3. Beemster, G.; Baskin, T.I. Analysis of Cell Division and Elongation Underlying the Developmental Acceleration of Root Growth in Arabidopsis thaliana. Plant Physiol. 1998, 116, 1515-1526. [CrossRef]

4. Chaiwanon, J.; Wang, W.; Zhu, J.-Y.; Oh, E.; Wang, Z.-Y. Information Integration and Communication in Plant Growth Regulation. Cell 2016, 164, 1257-1268. [CrossRef] [PubMed]

5. Zhu, J.-Y.; Sae-Seaw, J.; Wang, Z.-Y. Brassinosteroid signalling. Development 2013, 140, 1615-1620. [CrossRef] [PubMed]

6. Chaiwanon, J.; Wang, Z.-Y. Spatiotemporal Brassinosteroid Signaling and Antagonism with Auxin Pattern Stem Cell Dynamics in Arabidopsis Roots. Curr. Biol. 2015, 25, 1031-1042. [CrossRef] [PubMed]

7. Tong, H.; Xiao, Y.; Liu, D.; Gao, S.; Liu, L.; Yin, Y.; Jin, Y.; Qian, Q.; Chu, C. Brassinosteroid Regulates Cell Elongation by Modulating Gibberellin Metabolism in Rice. Plant Cell 2014, 26, 4376-4393. [CrossRef]

8. González-García, M.-P.; Vilarrasa-Blasi, J.; Zhiponova, M.; Divol, F.; Mora-García, S.; Russinova, E.; Caño-Delgado, A.I. Brassinosteroids control meristem size by promoting cell cycle progression in Arabidopsis roots. Development 2011, 138, 849-859. [CrossRef] [PubMed]

9. Lynch, J.P. Root phenotypes for improved nutrient capture: An underexploited opportunity for global agriculture. New Phytol. 2019, 223, 548-564. [CrossRef] 
10. Rogers, E.D.; Benfey, P.N. Regulation of plant root system architecture: Implications for crop advancement. Curr. Opin. Biotechnol. 2015, 32, 93-98. [CrossRef]

11. Pandey, A.; Devi, L.L.; Singh, A.P. Review: Emerging roles of brassinosteroid in nutrient foraging. Plant Sci. 2020, $296,110474$. [CrossRef]

12. Jia, Z.; Giehl, R.F.H.; Meyer, R.C.; Altmann, T.; Von Wirén, N. Natural variation of BSK3 tunes brassinosteroid signaling to regulate root foraging under low nitrogen. Nat. Commun. 2019, 10, 2378. [CrossRef] [PubMed]

13. Jia, Z.; Giehl, R.F.; von Wirén, N. The Root Foraging Response under Low Nitrogen Depends on DWARF1-Mediated Brassinosteroid Biosynthesis. Plant Physiol. 2020, 183, 998-1010. [CrossRef]

14. Hartwig, T.; Corvalán, C.; Best, N.B.; Budka, J.S.; Zhu, J.-Y.; Choe, S.; Schulz, B. Propiconazole Is a Specific and Accessible Brassinosteroid (BR) Biosynthesis Inhibitor for Arabidopsis and Maize. PLoS ONE 2012, 7, e36625. [CrossRef]

15. Wei, Z.; Li, J. Regulation of Brassinosteroid Homeostasis in Higher Plants. Front. Plant Sci. 2020, 11, 583622. [CrossRef] [PubMed]

16. Santuari, L.; Sanchez-Perez, G.F.; Luijten, M.; Rutjens, B.; Terpstra, I.; Berke, L.; Gorte, M.; Prasad, K.; Bao, D.; TimmermansHereijgers, J.L.; et al. The PLETHORA Gene Regulatory Network Guides Growth and Cell Differentiation in Arabidopsis Roots. Plant Cell 2016, 28, 2937-2951. [CrossRef]

17. Wang, Q.; Zhu, Y.; Zou, X.; Li, F.; Zhang, J.; Kang, Z.; Li, X.; Yin, C.; Lin, Y. Nitrogen Deficiency-Induced Decrease in Cytokinins Content Promotes Rice Seminal Root Growth by Promoting Root Meristem Cell Proliferation and Cell Elongation. Cells 2020, 9, 916. [CrossRef] [PubMed]

18. Guo, L.; Ho, C.-M.K.; Kong, Z.; Lee, Y.-R.J.; Qian, Q.; Liu, B. Evaluating the microtubule cytoskeleton and its interacting proteins in monocots by mining the rice genome. Ann. Bot. 2009, 103, 387-402. [CrossRef]

19. Ma, B.; Yin, C.-C.; He, S.-J.; Lu, X.; Zhang, W.-K.; Lu, T.-G.; Chen, S.-Y.; Zhang, J.-S. Ethylene-Induced Inhibition of Root Growth Requires Abscisic Acid Function in Rice (Oryza sativa L.) Seedlings. PLoS Genet. 2014, 10, e1004701. [CrossRef]

20. Lee, H.Y.; Yoon, G.M. Regulation of Ethylene Biosynthesis by Phytohormones in Etiolated Rice (Oryza sativa L.) Seedlings. Mol. Cells 2018, 41, 311-319. [CrossRef]

21. Wang, Y.; Zhao, Z.; Liu, F.; Sun, L.; Hao, F. Versatile Roles of Aquaporins in Plant Growth and Development. Int. J. Mol. Sci. 2020, 21, 9485. [CrossRef] [PubMed]

22. Gowda, V.R.; Henry, A.; Yamauchi, A.; Shashidhar, H.; Serraj, R. Root biology and genetic improvement for drought avoidance in rice. Field Crop. Res. 2011, 122, 1-13. [CrossRef]

23. Takatsuka, H.; Umeda, M. Hormonal control of cell division and elongation along differentiation trajectories in roots. J. Exp. Bot. 2014, 65, 2633-2643. [CrossRef] [PubMed]

24. Castorina, G.; Consonni, G. The Role of Brassinosteroids in Controlling Plant Height in Poaceae: A Genetic Perspective. Int. J. Mol. Sci. 2020, 21, 1191. [CrossRef] [PubMed]

25. Jiao, X.; Wang, H.; Yan, J.; Kong, X.; Liu, Y.; Chu, J.; Chen, X.; Fang, R.; Yan, Y. Promotion of BR Biosynthesis by miR444 Is Required for Ammonium-Triggered Inhibition of Root Growth. Plant Physiol. 2020, 182, 1454-1466. [CrossRef]

26. Fang, J.; Yuan, S.; Li, C.; Jiang, D.; Zhao, L.; Peng, L.; Zhao, J.; Zhang, W.; Li, X. Reduction of ATPase activity in the rice kinesin protein Stemless Dwarf 1 inhibits cell division and organ development. Plant J. 2018, 96, 620-634. [CrossRef]

27. Li, J.; Jiang, J.; Qian, Q.; Xu, Y.; Zhang, C.; Xiao, J.; Du, C.; Luo, W.; Zou, G.; Chen, M.; et al. Mutation of Rice BC12/GDD1, Which Encodes a Kinesin-Like Protein That Binds to a GA Biosynthesis Gene Promoter, Leads to Dwarfism with Impaired Cell Elongation. Plant Cell 2011, 23, 628-640. [CrossRef]

28. Sazuka, T.; Aichi, I.; Kawai, T.; Matsuo, N.; Kitano, H.; Matsuoka, M. The Rice Mutant dwarf bamboo shoot 1: A Leaky Mutant of the NACK-type Kinesin-like Gene Can Initiate Organ Primordia but not Organ Development. Plant Cell Physiol. 2005, 46, 1934-1943. [CrossRef]

29. Ruan, Y.; Halat, L.S.; Khan, D.; Jancowski, S.; Ambrose, C.; Belmonte, M.F.; Wasteneys, G.O. The Microtubule-Associated Protein CLASP Sustains Cell Proliferation through a Brassinosteroid Signaling Negative Feedback Loop. Curr. Biol. 2018, 28, 2718-2729.e5. [CrossRef]

30. Zou, X.; Shao, J.; Wang, Q.; Chen, P.; Zhu, Y.; Yin, C. Supraoptimal Cytokinin Content Inhibits Rice Seminal Root Growth by Reducing Root Meristem Size and Cell Length via Increased Ethylene Content. Int. J. Mol. Sci. 2018, 19, 4051. [CrossRef] [PubMed]

31. De Vleesschauwer, D.; Van Buyten, E.; Satoh, K.; Balidion, J.; Mauleon, R.; Choi, I.-R.; Vera-Cruz, C.; Kikuchi, S.; Höfte, M. Brassinosteroids Antagonize Gibberellin- and Salicylate-Mediated Root Immunity in Rice. Plant Physiol. 2012, 158, 1833-1846. [CrossRef]

32. Cheng, L.; Li, M.; Min, W.; Wang, M.; Chen, R.; Wang, W. Optimal Brassinosteroid Levels Are Required for Soybean Growth and Mineral Nutrient Homeostasis. Int. J. Mol. Sci. 2021, 22, 8400. [CrossRef] [PubMed]

33. Vukašinović, N.; Wang, Y.; Vanhoutte, I.; Fendrych, M.; Guo, B.; Kvasnica, M.; Jiroutová, P.; Oklestkova, J.; Strnad, M.; Russinova, E. Local brassinosteroid biosynthesis enables optimal root growth. Nat. Plants 2021, 7, 619-632. [CrossRef] [PubMed]

34. Yoshida, S. Routine Procedure for Growing Rice Plants in Culture Solution. In Laboratory Manual for Physiological Studies of Rice; International Rice Research Institute: Manila, Philippines, 1976; pp. 61-66.

35. Kim, B.K.; Fujioka, S.; Takatsuto, S.; Tsujimoto, M.; Choe, S. Castasterone is a likely end product of brassinosteroid biosynthetic pathway in rice. Biochem. Biophys. Res. Commun. 2008, 374, 614-619. [CrossRef] [PubMed] 
36. Aldukhi, F.; Deb, A.; Zhao, C.; Moffett, A.S.; Shukla, D. Molecular Mechanism of Brassinosteroid Perception by the Plant Growth Receptor BRI. J. Phys. Chem. B 2020, 124, 355-365. [CrossRef]

37. Xu, Y.; Zou, J.; Zheng, H.; Xu, M.; Zong, X.; Wang, L. RNA-Seq Transcriptome Analysis of Rice Primary Roots Reveals the Role of Flavonoids in Regulating the Rice Primary Root Growth. Genes 2019, 10, 213. [CrossRef]

38. Truernit, E.; Bauby, H.; Dubreucq, B.; Grandjean, O.; Runions, J.; Barthélémy, J.; Palauqui, J.-C. High-Resolution Whole-Mount Imaging of Three-Dimensional Tissue Organization and Gene Expression Enables the Study of Phloem Development and Structure inArabidopsis. Plant Cell 2008, 20, 1494-1503. [CrossRef] [PubMed]

39. Kim, D.; Langmead, B.; Salzberg, S.L. HISAT: A fast spliced aligner with low memory requirements. Nat. Methods 2015, 12, 357-360. [CrossRef]

40. Pertea, M.; Pertea, G.M.; Antonescu, C.M.; Chang, T.-C.; Mendell, J.T.; Salzberg, S.L. StringTie enables improved reconstruction of a transcriptome from RNA-seq reads. Nat. Biotechnol. 2015, 33, 290-295. [CrossRef]

41. Love, M.I.; Huber, W.; Anders, S. Moderated estimation of fold change and dispersion for RNA-seq data with DESeq. Genome Biol 2014, 15, 550. [CrossRef]

42. Ran, X.; Zhao, F.; Wang, Y.; Liu, J.; Zhuang, Y.; Ye, L.; Qi, M.; Cheng, J.; Zhang, Y. Plant Regulomics: A data-driven interface for retrieving upstream regulators from plant multi-omics data. Plant J. 2020, 101, 237-248. [CrossRef] [PubMed]

43. Supek, F.; Bošnjak, M.; Škunca, N.; Smuc, T. REVIGO Summarizes and Visualizes Long Lists of Gene Ontology Terms. PLoS ONE 2011, 6, e21800. [CrossRef] [PubMed]

44. Metsalu, T.; Vilo, J. ClustVis: A web tool for visualizing clustering of multivariate data using Principal Component Analysis and heatmap. Nucleic Acids Res. 2015, 43, W566-W570. [CrossRef] [PubMed] 